\title{
FUNCTIONAL LOAD WHEN PLAYING "MICRO-KORFBAL"
}

\author{
J. JONGE, M.D.
}

\section{Amsterdamse Straatweg 476, Utrecht, Netherlands}

\begin{abstract}
"Korfbal" is a mixed field sport quite popular in the Netherlands, imported from Sweden and modified to a real sport.

"Korfbal" is played by two teams of six women and six men playing on a ground divided into three sectors from which the competitors change sector after two goals. The question often put, is: should not the men be restrained because they have to play with women whose physical performances are behind of those of men in an important way on account of intrinsic properties? The medical doctor will perhaps add to this, the question whether the women might not be overloaded?
\end{abstract}

\section{Working method}

We put ourselves the question: would it be possible to learn more about the size of the effort which is asked from a woman and a man when playing the same "korfbal" match in the highest division? Translated into the language of occupational physiology the question is: "which part of the individual work capacity (e.g. to be measured on an ergometer bicycle) is asked from the woman or from the man when playing such a match? As a measure for this effort we chose the heart beat frequency, justified from experience in Occupational medicine. In ergonomics this can lead to a better judgment of labour fitness for a certain profession and of those who are handicapped by reduced capacities of the circulation or of the respiratory system.

The heart beat frequency is only one of the many parameters which can give an insight into the work load but it is the only datum that can be measured continuously without interfering perceptibly in the match so that the data can be collected as well during the whole test on the bicycle as during the whole "korfbal" match.

Besides the "field korfbal" as described in the beginning, "indoor korfbal" has also been developed, named "micro-korfbal".

It is different from field korfbal in so far that it is played by four women and four men in a sports hall, divided into two sectors instead of three so that the middle sector is missing. Moreover the duration of the match is not twice three quaters of an hour but twice half an hour. It is thought that this modification is more attractive for the spectator.
To do our experiments on "micro-korfbal" had also the advantage that we could use our equipment independently of the weather. We did these experiments during a specially organized match in order to test our equipment and on two matches in the top class of the competition of the national league.

\section{Results}

In the afternoon we did an ergometer test in which the subjects (three women and three men) performed an experiment on a bicycle according to Müller's technique with a load increasing with 10 Watts per minute, starting with 0 Watts till they could go no further, or until 250 Watts, the maximum load on this bicycle ergometer, had been achieved. From these experiments we got the following data:

\section{TABLE I}

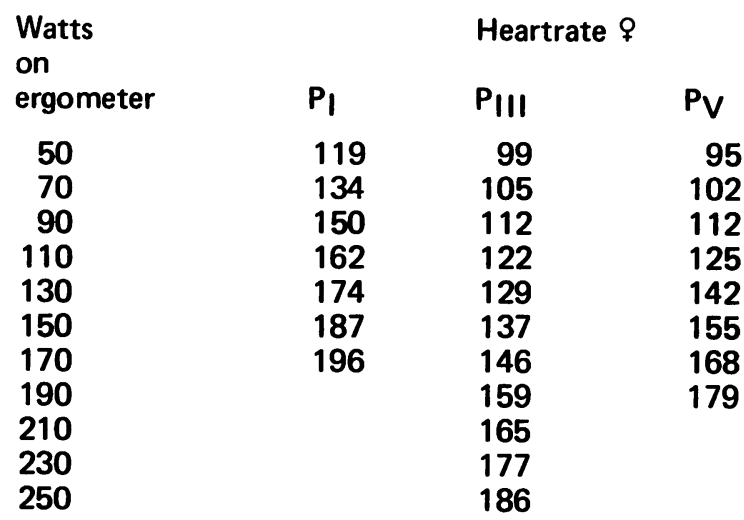

TABLE II

\begin{tabular}{lrrr}
$\begin{array}{l}\text { Watts } \\
\text { on } \\
\text { ergometer }\end{array}$ & \multicolumn{3}{c}{ Heartrate o } \\
50 & 81 & PIV & PVI \\
70 & 85 & 111 & 93 \\
90 & 93 & 109 & 100 \\
110 & 103 & 142 & 109 \\
130 & 113 & 140 & 114 \\
150 & 123 & 150 & 123 \\
170 & 133 & 162 & 130 \\
190 & 145 & 171 & 139 \\
210 & 154 & 176 & 147 \\
230 & 167 & 182 & 155 \\
250 & 177 & 183 & 171
\end{tabular}


These data can be shown in a diagram:
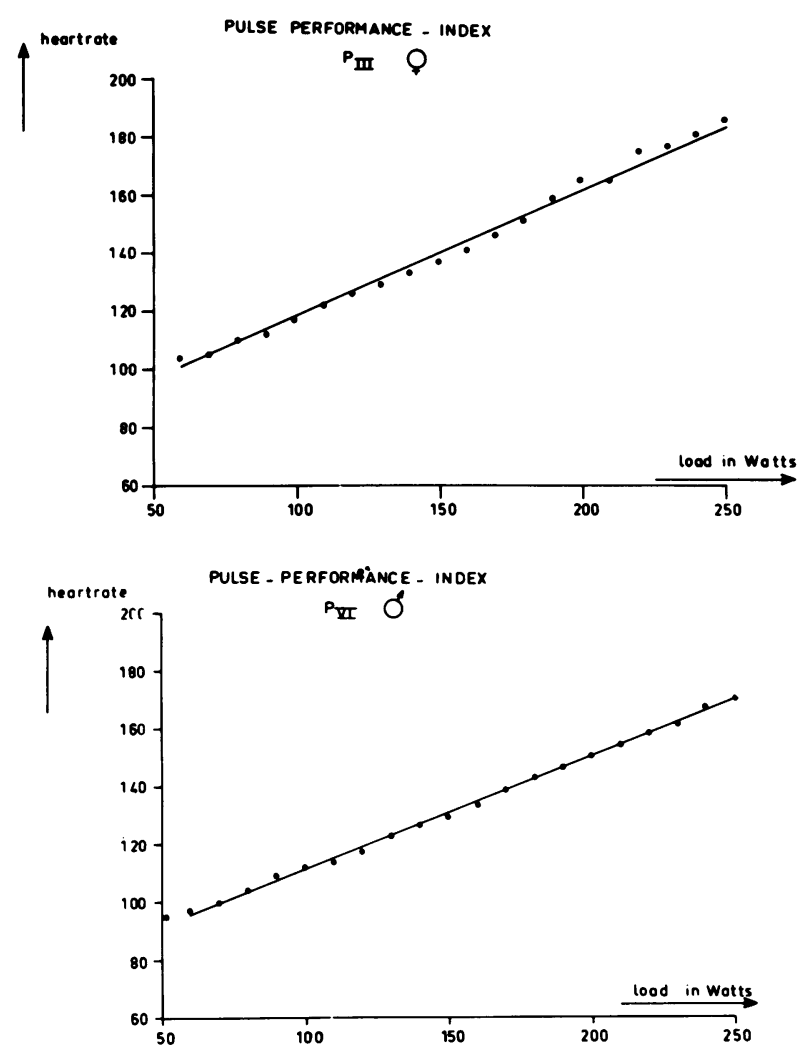

This results in the following P.P.I. of our six subjects. We like to mention that two of the subjects did not belong to the top class and that subject no. 5 was not in an optimal condition because of family circumstances.

TABLE III

$\begin{array}{llll}\text { testee } & \text { age } & \begin{array}{l}\text { P.P.I. } \\ \text { after a load } \\ \text { of } 60 \text { Watts }\end{array} \\ \text { PI } & \$ & 22 & 5.8 \\ \text { PII } & \delta & 24 & 5.0 \\ \text { PIII } & + & 21 & 4.3 \\ \text { PIV } & \delta & 22 & 3.6 \\ \text { PV } & \$ & 23 & 6.2 \\ \text { PVI } & \delta & 20 & 3.9\end{array}$

During the match which took place on the same day in the evening after quite a long rest period, the following heart beat frequencies were found: directly written on millimeter paper ( 3 lines $=1$ minute).

The average heart rate was respectively:

with the exception of subject no. 1 the average heart rate of all subjects (women and men) was about the same as well as before the rest break as after it. The slight differences become still smaller if the length of time that the ball was in the playing sector of the concerning subject is taken into account.

\section{TABLE IV}

\begin{tabular}{|c|c|c|c|}
\hline \multirow{2}{*}{\multicolumn{2}{|c|}{ testee }} & \multicolumn{2}{|c|}{$\begin{array}{l}\text { average heartrate } \\
+ \text { S.D. }\end{array}$} \\
\hline & & before interval & after interval \\
\hline$P_{1}$ & q & $196 \pm 7$ & $195 \pm 8$ \\
\hline$P_{11}$ & $\delta$ & $174 \pm 10$ & $177 \pm 8$ \\
\hline PIII & q & $170 \pm 15$ & $169 \pm 12$ \\
\hline PIV & $\delta$ & $178 \pm 6$ & $177 \pm 7$ \\
\hline PV & q & $171 \pm 8$ & $173 \pm 8$ \\
\hline PVI & ot & $182 \pm 5$ & $171 \pm 12$ \\
\hline
\end{tabular}

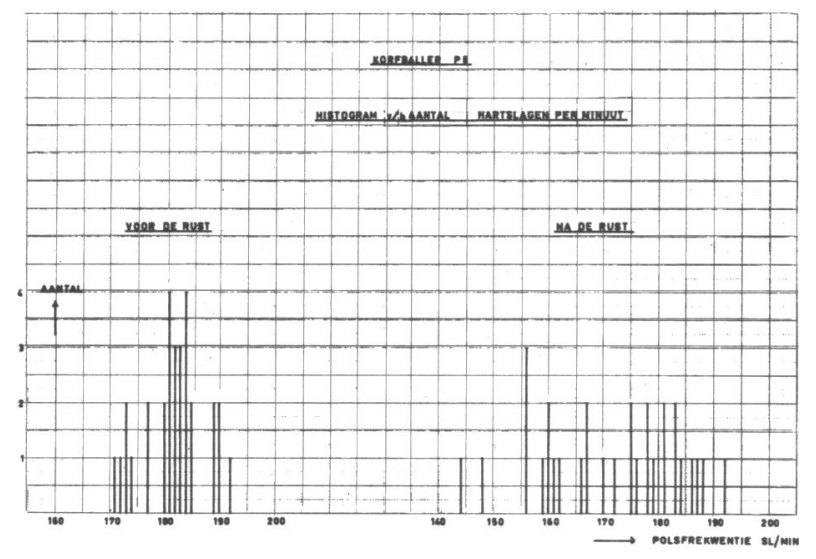

One can see that the spreading of the number of minutes that a certain heart beat frequency is measured, increase and with this also the standard deviation if the ball is in the section for a shorter time.

\section{TABLE V}

minutes that the ball was in playing sector

match testee

before interval after interval

$\begin{array}{lllll}\text { A } & \text { PI } & \text { } & 17 & 16 \\ \text { A } & \text { PII } & \text { o } & 17 & 16 \\ \text { B } & \text { PIII } & \text { } & 14 & 13 \\ \text { B } & \text { PIV } & \text { o } & 16 & 17 \\ \text { C } & \text { PV } & \text { \& } & 13 & 181 / 2 \\ \text { C } & \text { PVI } & \text { o } & 17 & 111 / 2\end{array}$

\section{Discussions and Conclusions}

1. For an investigation into the quantitative load of sport exercise on the human organism the comparison with the results of tests on an bicycle ergometer is not usable. This is in contradistinction to the research in the field of Occupational medicine where mostly one deals with a lower load which however, has to be sustained during an uncomparable, much longer time.

The continuous load during 25 minutes which is asked from the subject in our experiments on the bicycle ergometer is of quite another nature than the short duration repeated activities asked from a participant in a "micro-korfbal" match.

A subject on a bicycle ergometer is exhausted for a short time after termination of the experiment. Such a form of exhaustion is never seen during a "micro-korfbal" match, because the efforts are divided, as one may understand. Nevertheless a very high heart beat frequency is found during the whole match.

2. Another argument which leads to the same conclusion is the observation that the heart beat frequency of our subjects never decreases beneath 150 beats per minute during the match; this is only partly to be explained by the physical effort. This phenomenon has to be seen rather as an expression of mental load being the consequence of effort and willpower.

In addition we refer to our observation that already before the start of a match and directly after that start each participant has a heart beat frequency much higher than at rest or when standing still.

3. We point out the immediate influence of suddenly increasing activity on the heart rate during all matches. These reactions are so quick that we could not explain these phenomena but as a reflex action of the muscles on the heart, perhaps by training conditionally quickened.

4. Rather than using the values obtained with the bicycle ergometer experiment as a reference for the work capacity in sport we should like to use the maximum heart beat frequency which in general is limited to $\mathbf{2 0 0}$ or a little more. Starting from this point we see in our experiments nearly the same effort in men and women.

How far this is the real maximum can only be judged when more experiments have been done in comparable team field sports which among others are characterized by changes in maximum physical activities and relative breaks.

Moreover a comparison of the work capacity of the 
male and female participants in different team field sports could not be missed.

5. The point of view defended by us, that the functional load of women and men is nearly the same, at least according to the relation of the heart rate and the maximum frequency, will not say that the man is not doing more physical labour during the match than the woman. This can, as everybody knows, never be expected because of the big differences in physical capacities between both sexes. So we are seeing quite clearly a division of work; part of the tactics of the "korfbal" match.

6. However this means according to us that conditioning training of women and men must be always separated because giving the same instructions to both sexes gives a possibility of underloading the men and overloading the women, which makes the results of this training at least doubtful.

7. Once again we emphasize the high average heart rate (nearly 200) of our first female subject. When one follows this train of thoughts this means that this woman loaded her heart heavily by participating in this "micro-korfbal" match in spite of, or perhaps thanks to, the fact that she did not belong to the top class players. This would give according to me an indication that the demands in a medical examination for competitive sport may be independent of the class in which one plays. Perhaps the opposite could be concluded from this single observation.

\title{
POSTURAL TRAINING IN ATHLETES
}

W. E. TUCKER, F.R.C.S.

71 Park Street, London, W.1

\begin{abstract}
The prevention of athletic injuries and their recurrences should be an essential part of athletic training. In the comprehensive treatment of athletic injuries, treatment by a team of experts is essential. Each member should be so well trained in his particular branch, that the athlete should receive first-class treatment at every stage. There must be efficient first-aid treatment. After an exact diagnosis using all the available ancillary methods, the surgeon details his recommendations. Operation may be necessary. The nature of his injury is explained to the athlete, and it must be stressed to him that he can contribute greatly to his recovery by conscientious and regular self-treatment at home. The physiotherapist is called in to help almost immediately. In due course, the injured athlete is referred to the trainer with exact instructions.
\end{abstract}

Many athletic injuries occur and recur because the athlete has not been taught the essentials of body mechanics.

The individual, however, can decide whether the way he carries himself in the upright position is one of Active Alerted, Balanced Posture; or the opposite, an inactive unbalanced slumping one. Posture therefore in the upright position is entirely an individual attitude of mind.

A failure to appreciate the importance of correct posture allows a gravity strain on the lower fixed parts - and may predispose towards fibrosity, myalgia, joint strain progressing to arthritis, metatarsalgia, subluxation of the hip, prolonged intavertebral disc, abdominal herniae and cervical spondylosis.

NOTE

For a full description, the reader is referred to Mr. W. E. Tucker's monograph "Active Alerted Posture" (1960) Published by E. and S. Livingstone - Edinburgh.

\section{DISABILITIES OF THE ELBOW JOINT}

\section{W. E. TUCKER, F.R.C.S.}

The structure of the joint was described, and its dislocations and injuries to the surrounding muscles are described.

The full text was published in the British Journal of Sports Medicine, Vol. VI, 69-75, 1972 